\title{
Atherosclerosis
}

\section{SAFEHEART risk-equation and cholesterol-year-score are powerful predictors of cardiovascular events in French patients with Familial Hypercholesterolemia --Manuscript Draft--}

\begin{tabular}{|c|c|}
\hline Manuscript Number: & ATH-D-20-00496R1 \\
\hline Article Type: & Research paper \\
\hline Section/Category: & Clinical \& Population Research \\
\hline Keywords: & $\begin{array}{l}\text { familial hypercholesterolemia; cardiovascular risk, cardiovascular risk equation; } \\
\text { cholesterol-year-score; primary cardiovascular prevention }\end{array}$ \\
\hline Corresponding Author: & $\begin{array}{l}\text { Sophie Béliard, MD, PhD } \\
\text { Aix Marseille Univ, INSERM, INRA, C2VN, Marseille, France } \\
\text { Marseille, FRANCE }\end{array}$ \\
\hline First Author: & Antonio Gallo \\
\hline \multirow[t]{11}{*}{ Order of Authors: } & Antonio Gallo \\
\hline & Sybil Charrières \\
\hline & Alexandre Vimont \\
\hline & John Chapman \\
\hline & Denis Angoulvant \\
\hline & Franck Boccara \\
\hline & Bertrand Cariou \\
\hline & valérie carreau \\
\hline & Alain Carrié \\
\hline & Eric Bruckert \\
\hline & Sophie Béliard, MD, PhD \\
\hline Abstract: & $\begin{array}{l}\text { Background and aims: Patients with heterozygous Familial Hypercholesterolemia } \\
\text { (HeFH) present elevated cardiovascular (CV) risk. Current CV risk stratification } \\
\text { algorithms developed for the general population are not adapted for heFH patients. It is } \\
\text { therefore of singular importance to develop and validate CV prediction tools which are } \\
\text { dedicated to the HeFH population. Methods: Our first objective was to validate the } \\
\text { Spanish SAFEHEART-risk equation (RE) in the French HeFH cohort (REFERCHOL), } \\
\text { and the second to compare SAFEHEART-RE with the low-density-lipoprotein- } \\
\text { cholesterol (LDL-C)-year-score for the prediction of CV events in the HeFH French } \\
\text { population. Results: We included HeFH (n=1473) patients with a genetic or clinical } \\
\text { diagnosis (DLCN score } \geq 8 \text { ). Among them, } 512 \text { patients with a 5-year follow-up were } \\
\text { included in order to validate the } 5 \text { year-CV-RE. A total of } 152 \text { events (10.3\%) occurred } \\
\text { in the entire population of } 1473 \text { patients during a mean follow-up of } 3.9 \text { years. Over the } \\
\text { five-year follow-up, non-fatal CV events occurred in } 103 \text { patients (20.2\%). Almost all } \\
\text { the parameters used in the SAFEHEART-RE were confirmed as strong predictors of } \\
\text { CV events in the REFERCHOL cohort. The C-statistic revealed a satisfactory } \\
\text { performance of both the SAFEHEART-RE and LDL-C-year-scores in predicting CV } \\
\text { events for all the patients (primary and secondary prevention) (C-index 0.77 and } 0.70 \text {, } \\
\text { respectively) as well as for those in primary prevention at the inclusion (C-index } 0.78 \\
\text { and } 0.77 \text {, respectively). Conclusion: This analysis represents the first external } \\
\text { validation of the SAFEHEART-RE and demonstrated that both SAFEHEART-RE and } \\
\text { the LDL-C-year-score are good predictors of CV events in primary prevention HeFH } \\
\text { patients. Abstract word count: } 249 \text { words Registry REFERCHOL, was declared to the } \\
\text { ANSM (the French National Agency for Medicines safety) and received an ID-RCB } \\
\text { declarant number: } 2014-A 01549-38 \text { Key words: familial hypercholesterolemia, } \\
\text { cardiovascular risk, cardiovascular risk equation, cholesterol-year-score, primary }\end{array}$ \\
\hline
\end{tabular}


cardiovascular prevention

Powered by Editorial Manager ${ }^{\circledR}$ and ProduXion Manager ${ }^{\circledR}$ from Aries Systems Corporation 
SAFEHEART-risk equation can now be used in other European population of HeFH patients to predict CV events

The cholesterol-year-score is a robust predictor of CV events in HeFH patients

SAFEHEART-RE and the cholesterol-year-score are valid in primary prevention heFH patients 


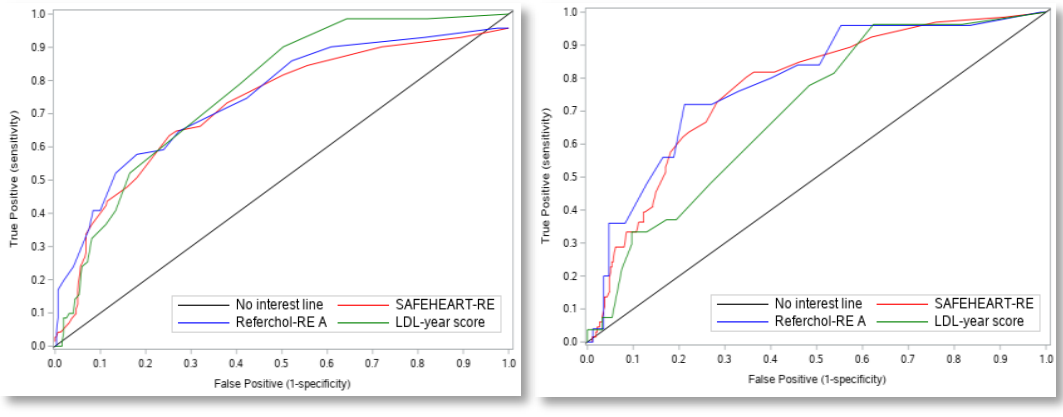

SAFEHEART-RE and LDL-C-year-score are good predictors of CV events in

patients with heterozygous Familial Hypercholesterolemia in primary

prevention (left ROC curves) and in primary and secondary prevention (right ROC curves) 
SAFEHEART risk-equation and cholesterol-year-score are powerful predictors of cardiovascular events in French patients with Familial Hypercholesterolemia

Antonio Gallo ${ }^{1 *}$, Sybil Charrières ${ }^{2 *}$, Alexandre Vimont ${ }^{3}$, M. John Chapman ${ }^{4}$, Denis Angoulvant ${ }^{5}$, Franck Boccara ${ }^{6}$, Bertrand Cariou ${ }^{7}$, Valérie Carreau ${ }^{1}$, Alain Carriée ${ }^{8}$, Eric Bruckert ${ }^{1}$, Sophie Béliard ${ }^{9}, 10$ for the REFERCHOL investigators

1. Department of Endocrinology and Prevention of Cardiovascular Disease, Institute of Cardio Metabolism And Nutrition (ICAN), La Pitié-Salpêtrière Hospital, AP-HP, Paris, France

2. Hospices Civils de Lyon, Endocrinology Department, Bron, University of Lyon 1, France

3. Public Health Expertise, Paris, France.

4. Sorbonne University, INSERM and Endocrinology-Metabolism Division, Pitie-Salpetriere University Hospital, Paris, France.

5. Tours university \& CHRU de Tours, Cardiology department \& EA4245 T2i, Loire Valley Cardiovascular Collaboration, F37000, Tours, France.

6. AP-HP, Hôpitaux de l'Est Parisien, Hôpital Saint-Antoine, Service de Cardiologie Faculty of Medicine, Sorbonne Université, National Institute of Health and Medical Research, INSERM, UMR_S 938, UPMC, Paris, France

7. L'institut du thorax, Endocrinology department, CIC 1413 INSERM, CHU de Nantes, Nantes, France

8. Sorbonne University, Inserm, Institute of Cardiometabolism and Nutrition (ICAN), UMR_S1166, APHP, Department of Biochemistry, Obesity and Dyslipidemia Genetics Unit, Hôpital de la Pitié, Paris, France

9. Aix Marseille University, INSERM, INRA, C2VN, Marseille, France

10. Department of Nutrition, Metabolic Diseases, Endocrinology, La Conception Hospital, Marseille, France

*: equally contributed to the work

French REgistry of Familial hypERCHOLesterolemia (REFERCHOL) : Denis ANGOULVANT, Sophie BELIARD, Franck BOCCARA, Eric BRUCKERT, Bertrand CARIOU, Valérie CARREAU, Alain CARRIE, Sybil CHARRIERES, Yves COTTIN, Mathilde DI FILIPPO, Sonia DULONG, Vincent DURLACH, Michel FARNIER, Emile FERRARI, Dorota FERRIERES, Jean FERRIERES, Antonio GALLO, Philippe GIRAL, Sophie GONBERT, Regis HANKARD, Jocelyn INAMO, Olga KALMYKOVA, Michel KREMPF, Philippe MOULIN, François PAILLARD, Noel PERETTI, Agnes PERRIN, Jean Pierre RABES, Ariane SULTAN, Patrick TOUNIAN, René VALERO, Bruno VERGES, Cecile YELNIK, Olivier ZIEGLER

Short title: Cardiovascular risk prediction in French HeFH patients 
Previous presentations: This manuscript has not been published in this or any substantially similar form, nor accepted, nor is it under consideration for publication elsewhere. This work was presented as an oral communication at the EAS congress in 2018.

Supports: This work was supported by the French national project CHOPIN (CHolesterol Personalized INnovation) funded by the Agence Nationale de la Recherche (ANR-16-RHUS-0007) and coordinated by the $\mathrm{CHU}$ of Nantes.

\section{Corresponding author:}

Dr Sophie Béliard

APHM, Department of Nutrition, Metabolic diseases, Endocrinology, La Conception Hospital, Aix Marseille University, INSERM, INRA, C2VN, Marseille, France

147 boulevard Baille, 13005 Marseille, France

Phone number: 0033491383650

Fax number: 0033491384132

Email : sophie.beliard@ap-hm.fr

Word count: 6528 words

Text: 3981 words

Bibliography: 1047 words

3 figures and 3 tables $=250 \times 6=1500$ words 
Abstract:

Background and aims: Patients with heterozygous Familial Hypercholesterolemia $(\mathrm{HeFH})$ present elevated cardiovascular (CV) risk. Current CV risk stratification algorithms developed for the general population are not adapted for heFH patients. It is therefore of singular importance to develop and validate CV prediction tools which are dedicated to the HeFH population.

Methods: Our first objective was to validate the Spanish SAFEHEART-risk equation (RE) in the French HeFH cohort (REFERCHOL), and the second to compare SAFEHEART-RE with the lowdensity-lipoprotein-cholesterol (LDL-C)-year-score for the prediction of CV events in the HeFH French population.

Results: We included HeFH ( $n=1473$ ) patients with a genetic or clinical diagnosis (DLCN score $\geq 8$ ). Among them, 512 patients with a 5-year follow-up were included in order to validate the 5 yearCV-RE. A total of 152 events (10.3\%) occurred in the entire population of 1473 patients during a mean follow-up of 3.9 years. Over the five-year follow-up, non-fatal CV events occurred in 103 patients (20.2\%). Almost all the parameters used in the SAFEHEART-RE were confirmed as strong predictors of $\mathrm{CV}$ events in the REFERCHOL cohort. The C-statistic revealed a satisfactory performance of both the SAFEHEART-RE and LDL-C-year-scores in predicting CV events for all the patients (primary and secondary prevention) ( $\mathrm{C}$-index 0.77 and 0.70 , respectively) as well as for those in primary prevention at the inclusion (C-index 0.78 and 0.77 , respectively).

Conclusion: This analysis represents the first external validation of the SAFEHEART-RE and demonstrated that both SAFEHEART-RE and the LDL-C-year-score are good predictors of CV events in primary prevention HeFH patients.

Abstract word count: 249 words

Registry REFERCHOL, was declared to the ANSM (the French National Agency for Medicines safety) and received an ID-RCB declarant number: 2014-A01549-38

Key words: familial hypercholesterolemia, cardiovascular risk, cardiovascular risk equation, cholesterol-year-score, primary cardiovascular prevention 
Introduction

Heterozygous Familial Hypercholesterolemia $(\mathrm{HeFH})$ is one of the most prevalent autosomal dominant genetic diseases, and is characterized by mutations in genes encoding proteins involved in low-density-lipoprotein-cholesterol (LDL-C) catabolism. As a consequence, $\mathrm{HeFH}$ patients feature elevated circulating levels of LDL-C from birth. This condition remains underdiagnosed and undertreated, (1) (2) (3) and is characterized by premature cardiovascular (CV) events driven by lifelong exposure of the arterial wall to hypercholesterolemia (4).

Traditional risk factors such as smoking and hypertension may further increase CV risk in HeFH patients. Indeed, cumulative traditional CV risk factors are currently used to classify HeFH patients into categories of lesser or greater severity $(5,6)$. Cardiovascular risk is however expressed heterogeneously among HeFH patients (7). It is therefore essential to identify the more severe patients early in life, and to initiate treatment to the guideline-recommended goal of LDL-C commensurate with their level of risk $(8,9)$. Moreover, it is of particular importance to precisely evaluate $\mathrm{CV}$ risk in primary prevention HeFH patients, in order to guide the choice of the type and the frequency of CV explorations, the initiation of aspirin or PCSK9 inhibitors.

Classical CV risk equations (RE), such as the European SCORE equation or the US Framingham RE were formulated with data from the general population and are not therefore recommended for application to FH patients, as they underestimate their CV risk (1). Moreover, the SCORE RE is only valid for persons older than 40 years-old.

Recently, Pérez de Isla et al. developed the first specific CV-RE dedicated to genetically-confirmed HeFH patients, in primary or in secondary prevention: the SAFEHEART-RE (10) (11). This algorithm was constituted of traditional risk factors: age, gender, smoking, hypertension, body mass index, a history of $C V$ events, and levels of $L D L-C$ and lipoprotein (a) ( $L p(a))$. To date, the SAFEHEART RE has not been validated in another HeFH cohort and has not been tested in patients free of $\mathrm{CV}$ events at the inclusion. An external validation is critical for the extension of this CV-RE to other HeFH populations.

The cholesterol-year-score is a simple tool which evaluates the duration and the intensity of vascular exposure to elevated cholesterol levels (12), and in a similar manner to that in which pack-year is used to measure lifelong exposure to tobacco. An increased prevalence of early 
atherosclerotic burden has been observed in young HeFH subjects who present a high vascular cholesterol burden (13). The cholesterol-year-score was first used in homozygous FH subjects (12) but its validation in HeFH patients has not been reported to date. To our knowledge, the predictive power of the cholesterol-year-score in such subjects with respect to CV events has not yet been evaluated.

Our first objective was the validation of the Spanish SAFEHEART-RE in our French cohort of HeFH patients (REFERCHOL cohort), and the second, a comparison of the predictive power of SAFEHEART-RE with that of the LDL-C-year-score for CV events, in the whole cohort and in primary prevention $\mathrm{HeFH}$ patients.

\section{Patients and Methods}

\section{Study Design and Population}

The national French Register of FH (REFERCHOL) was established in 2015 by the Nouvelle Société Francophone d'Athérosclérose (NSFA) as previously described (14). For the present study, the population was prospectively enrolled between November 2015 and December 2018 and retrospective data were recorded from 2005 to 2015. A total of 2311 adults ( $\geq 18$ years old) with either a genetic or a clinical diagnostic (DLCN score $\geq 8$ ) of HeFH were enrolled. Among them, 1473 patients with at least two visits in the participating lipid clinics were retained for the analysis (Flow chart,

). For the validation of the 5 year CV-RE, we included 512 patients with either 5 -years of followup, or a CV event within the 5 years following the enrollment visit.

\section{Collection of Patient data}

Demographic and clinical characteristics at the enrollment visit (baseline) were used in this study. For most patients, DNA was isolated and the genetic diagnosis of FH was evaluated. Maximum statin dose was defined as previously described (atorvastatin 40 or 80 mg/day, rosuvastatin 20 or $40 \mathrm{mg} /$ day, or simvastatin $80 \mathrm{mg} /$ day) (15). Maximum combined lipid-lowering therapy was defined as maximum statin dose plus ezetimibe $10 \mathrm{mg} /$ day. Assessment of biological parameters, including a plasma lipid profile, were performed in the clinical laboratory attached to each lipid clinic, using assay methods subject to quality control. The majority of $L p(a)$ measurements were 
made using an immunonephelometric method (Siemens-France). However, some Lp(a) measurements were made with alternative methods in laboratories of other University Medical Centres, the latter corresponding to the location of heFH patients. The LDL-C-year-score was calculated as previously described by multiplying the highest LDL-C value by the patient's age at clinical diagnosis or at the initiation of statin therapy, to which was added the LDL-C value at the inclusion visit in the registry multiplied by the time spent until the inclusion visit, as follows: LDLC-year-score $=L D L-C$ max * [age at diagnosis/initiation of statin] $+L D L-C$ at inclusion * [age at inclusion - age at diagnosis/initiation of statin therapy]

\section{Definition of outcomes}

Cardiovascular events included coronary heart disease (acute coronary syndromes, myocardial infarction and unstable angina, percutaneous coronary intervention or coronary artery bypass graft), stroke or transient ischemic attack, peripheral artery disease (defined as carotid endarterectomy, carotid angioplasty, peripheral artery angioplasty or bypass), resuscitated sudden death and cardiovascular death (16). A family history of early CV events was defined as the occurrence of the first event before 55 years of age in men and before 65 years of age in women in first-degree relatives. The duration of follow-up was defined as the time from the enrollment visit to the last available visit at the Lipid Clinic.

\section{Statistical analysis}

These analyses were conducted in accordance with the TRIPOD (Transparent Reporting of a Multivariable Prediction Model for Individual Prognosis or Diagnosis) requirements (17). Univariate effects were analyzed with Cox models by hazard ratios and their 95\% confidence intervals. For multivariate analysis, several Cox models were adjusted. REFERCHOL equation A was estimated by forcing variables derived from SAFEHEART-RE in order to compare effect size regardless of statistical significance. REFERCHOL equation B included only independent significant factors with a $p$ value $<0.05$ from the analysis population. We modified some parameters as compared to the SAFEHEART cohort. First, maximal LDL-cholesterol (ie LDL-C before treatment) was not extrapolated from LDL-C under lipid lowering therapy but obtain from patient's medical record. Secondly, the segmentation for ranks according to LDL-C levels was modified in view of differences in sample sizes: there were only 91 patients with $L D L<100 \mathrm{mg} / \mathrm{dL}$ and 427 between 
100 and $160 \mathrm{mg} / \mathrm{dL}$. New cut-points for LDL-C were updated from <100 mg/dl in SAFEHEART-RE to $\leq 160 \mathrm{mg} / \mathrm{dL}$ as the reference level, to $160-200 \mathrm{mg} / \mathrm{dL}$ and to $>200 \mathrm{mg} / \mathrm{dL}$. LDL-C-year-score and the variables included in its calculation (age at initiation of statin treatment, maximum LDL-C before therapy) were also tested in the univariate analysis and LDL-C-year-score was included in the REFERCHOL Equation B.

As in SAFEHEART-RE, the Kaplan-Meier estimator from the analysis population to obtain the 5year risk was used according to the method described by D'Agostino (18). To compare ROC curves and C-indexes, the Kendall's Tau-b was computed to measures the ranking association between risk equations, and evaluated the concordance between pairs of estimated risks from two RE for every given risk threshold, ranging from -1 (negative association) to +1 (positive association). For additional validation of the Safeheart-RE and the REFERCHOL equation $A$, the degree of overoptimism (standard deviation from the standard error of risk estimations) on the REFERCHOL analysis population was estimated with bootstrap resampling of 100 randomized samples as recommended by TRIPOD (17). 
Results

\section{Characteristics of the HeFH REFERCHOL population at the enrollment visit}

The mean characteristics of the analysis population are presented in Table 1. The mean age of the patients was $49.6 \pm 16.7$ years. Genetic causal mutations were found in $70.1 \%(n=1032)$ of the REFERCHOL cohort, with $88.9 \%$ in the $L D L R$ gene, $7.8 \%$ in the APOB gene and $3.4 \%$ in the PCSK9 gene. Among patients with a clinical diagnosis $(n=441)$, more than half $(n=236,53.5 \%)$ did not have a genetic test and a small number of them lacked detectable causal mutations ( $n=33,7.5 \%)$. For other patients ( $n=172,39 \%)$, genetic tests are in process. At the enrollment visit, a third of patients were not receiving lipid lowering therapy $(n=491,33.3 \%)$. Almost a quarter of patients were receiving maximally tolerated statin therapy and $40 \%$ were treated with maximum combined therapy (ie maximum tolerated statin therapy plus ezetimibe). The mean age at statin initiation was $32 \pm 14.3$ years. The characteristics of the SAFEHEART population used for the development of the SAFEHEART risk equation (10) are also presented in Supplemental data 1.

\section{Predictive factors for incident $\mathrm{CV}$ events in the REFERCHOL cohort}

A total of 152 events occurred in the entire population of 1473 patients included for the analysis (10.3\%) during a mean follow-up of 3.9 years (SD: 3.4 years; Med: 2.6 years). A large proportion of events occurred in patients with a history of CV events ( $n=79 / 326,24.2 \%)$; a small proportion of events occurred in patients free of CV events at the enrollment visit ( $n=73 / 1147,6.3 \%)$. KaplanMeier curves showing freedom from recurrent cardiovascular events in all patients, and patients with history of CV events or patients without history of CV events, are shown in Figure 2. Table 2 presents univariate analysis of predictors of incident CV events. With the exception of a family history of premature CV event, ApoAI and Lp(a) levels, the predictors observed in the SAFEHEART cohort were statistically significant in the REFERCHOL cohort and the effect size of HRs varied globally over a similar range. Among the additional variables in REFERCHOL, LDL-C-year score was the strongest predictor of CV events. Table 3 shows multivariate analysis for REFERCHOL equations A and B. Data on the HRs for patients from the SAFEHEART study are reported in the first column, and are compared to those of the REFERCHOL cohort. REFERCHOL equations $A$ and $B$ were tested in the entire REFERCHOL population of 1473 patients. The REFERCHOL equation-A was applied by forcing the inclusion of all the significant variables of the SAFEHEART study in the 
model. Significant variables in the multivariate analysis in the equation-A model were age, the history of a CV event, active smoking and LDL-C levels. The REFERCHOL equation-B was calculated with the inclusion of only significant variables from the univariate analysis in the REFERCHOL cohort: gender, history of CV events, LDL-C levels and LDL-C-year-score. As maximal LDL-C levels and the age of statin initiation were used for the calculation of the cholesterol-yearscore, they were removed from the multivariate analysis. Gender, history of CV events, LDL-C levels and LDL-C-year-score were independent CV risk predictors in the REFERCHOL cohort. LDLC-year score was a strong predictor for CV events, as HeFH patients with a LDL-C-year-score between 6000 and $16000 \mathrm{mg} / \mathrm{dL}$ had a 5.7 fold increased in CV risk $(95 \% \mathrm{Cl}, \mathrm{p}=0.09)$ and those with a cholesterol-year-score above $16000 \mathrm{mg} / \mathrm{dL}$ had a CV risk multiplied by 17.4 fold $(95 \% \mathrm{Cl}$, $p=0.006)$.

Validation of the SAFEHEART risk prediction model and comparison to REFERCHOL-RE and cholesterol-year-score for predicting CV events in the REFERCHOL cohort

The analysis of the validation population (512 patients with five-year follow-up or a CV event within the five-year following enrollment visit) showed non-fatal CV events occurring in 103 patients (20.1\%; 34 nonfatal myocardial infarctions, 28 coronary artery revascularization procedures or bypass, 22 unstable anginas, 18 nonfatal strokes or transient ischemic attacks). Among the 512 patients, 393 were in primary prevention at inclusion and 46 of them had a CV event within the five 5 years of follow-up (11.7\%). Among the 119 patients in secondary prevention at inclusion, 57 of them had a recurrent CV event (47.9\%) event. Only the first event during followup was considered for analysis.

Considering the 512 patients cohort (primary and secondary prevention patients at the inclusion), the C-index of SAFEHEART-RE for predicting five-year CV events in the REFERCHOL cohort was 0.77, and the C-index of REFERCHOL-RE A and the cholesterol-year-score were respectively 0.78 and 0.70 . Figure $3 \mathrm{~A}$ shows the ROC curves for the 3 models. The ability of SAFEHART-RE, REFERCHOL-RE and the LDL-C-year-score to predict five-year CV events was quite similar between the 3 models, although a little less effective for the LDL-C-year-score (supplemental data 2).

Considering the 393 patients cohort (primary prevention patients), the sensitivity analysis showed that the all three risk prediction models were good predictors of CV events in this patients free of CV event at the inclusion with the following C-indexes: 0.78 for SAFEHEART-RE, 0.79 for the 
REFERCHOL-RE A and 0.77 for the cholesterol-year-score. (Figure 3B and supplemental data 2). The population of the 119 patients in secondary prevention at the enrollment was too small to be analyzed separately with unstable and uninterpretable results (supplemental data 2).

To compare ROC curves and C-indexes, the Kendall's Tau-b was computed to measure the ranking association between risk equations. The results were as following: Safeheart RE vs Referchol RE: 0.92, Safeheart RE vs LDL-year score: 0.78, Referchol RE vs LDL-year score: 0.83 (Kendall's Tau-b ranging from -1 (negative association) to +1 (positive association)). Additional validation assessed with bootstrap resampling (100 randomized sample of the original dataset) showed a degree of over-optimism of 0.01 and 0.007 for SAFEHART-RE and REFERCHOL-RE respectively.

Discussion:

The estimation of CV risk in HeFH has led to the development of dedicated CV-RE derived from the earliest longitudinal, prospective studies of national HeFH cohorts. SAFEHEART-RE was the first European HeFH cohort to develop a prospective model of prediction of CV events in this pathology (10). However, an external validation has not been performed to date, mainly as a result of the quality of data collection (namely, the lack of a molecular diagnosis of FH), of a relatively shorter follow-up for the comparison of CV outcomes, and of incompatibility between the databases. Indeed, HeFH is characterized by marked phenotypic variability, which often occurs independently of a molecular diagnosis, and which makes lifelong-cholesterol exposure (the socalled cholesterol burden) potentially a major surrogate marker for future CV disease. Moreover, SAFEHEART-RE was developed in a mixt population of primary and secondary prevention patients.

In the present study, we validated two different tools for the prediction of CV events in HeFH patients, SAFEHEART-RE and the LDL-C-year-score. Both SAFEHEART-RE and LDL-C-year-score performed in a highly satisfactory manner as concerns the prediction of CV events in the whole REFERCHOL cohort and specifically in patients in primary prevention. To our knowledge, this is the first external validation of the Spanish CV risk equation SAFEHEART dedicated to familial hypercholesterolemia, and the first validation of this CV risk equation in the specific population of $\mathrm{HeFH}$ patients free of $\mathrm{CV}$ events at the inclusion. . 
Differences between the Spanish and the French heFH cohorts:

Our REFERCHOL cohort exhibited some differences as compared to that from Spain. First, patients included in the REFERCHOL cohort had either a genetic diagnosis with a heterozygous causal gene mutation, or a clinical diagnosis based on the DLCN score, whereas all patients belonging to the SAFEHEART cohort had a genetic diagnosis of HeFH. In order to be included in the study, a DLCN $\geq 8$ was needed, resulting in a more severe CV risk profile in the REFERCHOL cohort, the consequence of the absence of a molecular diagnosis (which itself accounts for a DLCN score =8). Indeed, $20.1 \%$ of the REFERCHOL cohort was in secondary prevention as compared to $10 \%$ in the Spanish cohort and a higher prevalence of personal and/or family history of CV events, as well as higher LDL-C levels and/or xanthoma, were observed in the REFERCHOL cohort as compared to that of SAFEHEART. Xanthoma are a well-known CV risk factor in $\mathrm{FH}$ as they are correlated with the cholesterol burden (19) (20). Moreover, patients in the REFERCHOL cohort were older (49.6 years vs 45.5 years) and cumulated more CV risk factors (hypertension prevalence $27.3 \%$ vs 14\%; LDL-C levels at the enrollment visit: $200 \mathrm{mg} / \mathrm{dL}$ vs $177 \mathrm{mg} / \mathrm{dL}$ and $\mathrm{Lp}(\mathrm{a})$ levels $44.5 \mathrm{mg} / \mathrm{dL}$ vs 38 $\mathrm{mg} / \mathrm{dL}$ ) than those in the SAFEHEART cohort. Together, these differences between the two cohorts may explain the finding that French patients were more clinically severe, but they equally reinforce the fact that the SAFEHEART-RE is valid in different populations of HeFH patients. We observed that one third of $\mathrm{HeFH}$ patients were not treated at the enrolment visit, which corresponds to the first visit to a specialist Lipid Clinic. This observation implies that a selection bias may be operative as more severe patients are probably referred to Lipid clinics, while less severe patients are probably followed by their general practitioner. Lipid lowering therapies are typically initiated and / or intensified in specialist lipid clinics. Furthermore, some patients exhibit statin intolerance and are therefore addressed to a specialist lipidologist.

The cholesterol-year-score, a simple tool to predict $\mathrm{CV}$ events in $\mathrm{HeFH}$ :

Cholesterol-year-score is an easy-to-use tool for the estimation of lifelong vascular exposure to elevated levels of lipoprotein cholesterol. The cholesterol-year-score was first used in the nineties as a tool for evaluating the duration and the severity of hypercholesterolemia in homozygous FH (12) (21). Twenty years later, the concept of cholesterol burden is at the forefront of care recommendations in $\mathrm{FH}$, and emphasizes the fact that lipid lowering treatment must be initiated early (1). An elevated cholesterol burden is associated with an increased atherosclerotic 
burden. In an earlier study, we showed that up to $40 \%$ of young HeFH subjects aged 20-45 years exhibited coronary artery calcification, which was itself frequently associated with a high cholesterol burden (13). Interestingly, late initiation of lipid-lowering therapy, indirectly resulting in a higher pre-treatment cholesterol burden, was in turn associated with a higher atherosclerotic burden. This relationship has been extensively observed in other $\mathrm{FH}$ registries: the risk of $\mathrm{CV}$ death related to $\mathrm{FH}$ diagnosis was increased despite treatment in subjects in whom the age of initiation of lipid lowering therapy was late. A recent long-term follow-up study of young $\mathrm{FH}$ patients and their unaffected siblings has shown that lipid-lowering treatment that is initiated early in life results in a lower subclinical atherosclerotic burden and a significantly lower CV morbidity and mortality as compared to those FH subjects in whom treatment was initiated later (22). In the present study, the LDL-C-year-score was a strong predictor of CV events in HeFH patients especially in those in primary prevention. The CV risk is multiplied by 5.7 fold for patients with a cholesterol-year-score between 6000 and $16000 \mathrm{mg} / \mathrm{dL}$ and by 17.4 fold for those with a cholesterol year score above $16000 \mathrm{mg} / \mathrm{dL}$. More interestingly, we observed that a LDL-C-year-score above $6000 \mathrm{mg} / \mathrm{dL}$ provided a similar CV risk as that in patients who had already presented clinically with a CV event, suggesting that earlier initiation of lipid lowering therapy might contribute to reduction in the incidence of CV events.

In the REFERCHOL cohort, the predictive power of cholesterol-year-score for CV events was as robust as SAFEHEART-RE for patients in primary prevention but quite less robust when considering all patients (primary and secondary prevention). Nonetheless, these results demonstrated that arterial exposure to cholesterol as evaluated by the LDL-C-year-score is a satisfactory predictor of CV events, especially in patients free of CV events and that it summarized the effect of all other variables. These results reinforce the well-known major role of cholesterol burden in the development of $\mathrm{CV}$ disease in $\mathrm{FH}$, as the duration and the severity of the hypercholesterolemia performs as well as the combination of other traditional risk factors in prediction of $\mathrm{CV}$ events.

\section{Other markers or predictors of CV risk in HeFH patients:}

We did not evaluate the burden of subclinical atherosclerosis in this study: carotid IMT is a valid marker for the assessment of early atherosclerosis, namely in FH children (23), although 
Differences between the analysis population $(n=1473)$ and the validation population $(n=512)$

HeFH patients with a 5-year follow-up presented a more severe clinical profile than those included for the complete analysis (20.1\% of CV events as compared to $10 \%$ respectively). This difference may be due to a recruitment bias as more severe patients tend to benefit more frequently from follow-up in specialist Lipid clinics, thereby explaining the longer follow-up. 
Conflicts of interest statement: SB have received honoraria for board, conferences, clinical trial or congress from Aegerion, Akcea, Elivie, Sanofi or Amgen. AV has no conflict of interest to declare. E.B. reports grants from Sanofi and Amgen, and personal fees from Aegerion, Danone, Genfit, MSD, Sanofi/Regeneron Pharmaceuticals, Inc., AstraZeneca, Servier, AMGEN, AKCEA, Mylan. 
Financial supports: This work was supported by the French National project CHOPIN (CHolesterol Personalized INnovation) funded by the Agence Nationale de la Recherche (ANR-16-RHUS-0007) and coordinated by the CHU of Nantes.

Author's contributions: SB and EB are the principal investigators of the REFERCHOL registry, they contributed to the design and the setting of the registry. AG, SC, SB and EB designed the study and wrote the manuscript. AV made the statistical analyses of the data. JC, DA, FB, BC, VC and AC are co-investigators of the REFERCHOL registry and they made a critical revision of the manuscript. SB and EB are the guarantors of this work and, as such, had full access to all the data in the study and take responsibility for the integrity of the data.

Acknowledgments: Authors thank Dr Blachier and Dr Leleu from PH Expertise for the help with the statistical analysis.

\section{References:}

1. Nordestgaard BG, Chapman MJ, Humphries SE, Ginsberg HN, Masana L, Descamps OS, et al. Familial hypercholesterolaemia is underdiagnosed and undertreated in the general population: guidance for clinicians to prevent coronary heart disease: consensus statement of the European Atherosclerosis Society. Eur Heart J. 2013 Dec;34(45):3478-90a.

2. Benn M, Watts GF, Tybjaerg-Hansen A, Nordestgaard BG. Familial hypercholesterolemia in the danish general population: prevalence, coronary artery disease, and cholesterol-lowering medication. J Clin Endocrinol Metab. 2012 Nov;97(11):3956-64.

3. Benedek P, Eriksson M, Duvefelt K, Freyschuss A, Frick M, Lundman P, et al. Genetic testing for familial hypercholesterolemia among survivors of acute coronary syndrome. J Intern Med. 2018 Dec;284(6):674-84.

4. Mundal L, Igland J, Ose L, Holven KB, Veierod MB, Leren TP, et al. Cardiovascular disease mortality in patients with genetically verified familial hypercholesterolemia in Norway during 19922013. Eur J Prev Cardiol. 2017 Jan;24(2):137-44.

5. Beliard S, Millier A, Carreau V, Carrie A, Moulin P, Fredenrich A, et al. The very high cardiovascular risk in heterozygous familial hypercholesterolemia: Analysis of 734 French patients. J Clin Lipidol. 2016 Sep-Oct;10(5):1129-36 e3.

6. Santos RD, Gidding SS, Hegele RA, Cuchel MA, Barter PJ, Watts GF, et al. Defining severe familial hypercholesterolaemia and the implications for clinical management: a consensus statement from the International Atherosclerosis Society Severe Familial Hypercholesterolemia Panel. Lancet Diabetes Endocrinol. 2016 Oct;4(10):850-61.

7. Sniderman AD, Tsimikas S, Fazio S. The severe hypercholesterolemia phenotype: clinical diagnosis, management, and emerging therapies. J Am Coll Cardiol. 2014 May 20;63(19):1935-47.

8. Mach F, Baigent C, Catapano AL, Koskinas KC, Casula M, Badimon L, et al. 2019 ESC/EAS Guidelines for the management of dyslipidaemias: lipid modification to reduce cardiovascular risk. Eur Heart J. 2019 Aug 31. 
9. Santos RD, Gidding SS, Hegele RA, Cuchel MA, Barter PJ, Watts GF, et al. Defining severe familial hypercholesterolaemia and the implications for clinical management: a consensus statement from the International Atherosclerosis Society Severe Familial Hypercholesterolemia Panel. Lancet Diabetes Endocrinol. 2016 May 27.

10. Perez de Isla L, Alonso R, Mata N, Fernandez-Perez C, Muniz O, Diaz-Diaz JL, et al. Predicting Cardiovascular Events in Familial Hypercholesterolemia: The SAFEHEART Registry (Spanish Familial Hypercholesterolemia Cohort Study). Circulation. 2017 May 30;135(22):2133-44.

11. Mata $\mathrm{P}$, Alonso R, Perez de Isla L. Atherosclerotic cardiovascular disease risk assessment in familial hypercholesterolemia: does one size fit all? Curr Opin Lipidol. 2018 Dec;29(6):445-52.

12. Schmidt HH, Hill S, Makariou EV, Feuerstein IM, Dugi KA, Hoeg JM. Relation of cholesterol-year score to severity of calcific atherosclerosis and tissue deposition in homozygous familial hypercholesterolemia. Am J Cardiol. 1996 Mar 15;77(8):575-80.

13. Gallo A, Giral P, Carrie A, Carreau V, Beliard S, Bittar R, et al. Early coronary calcifications are related to cholesterol burden in heterozygous familial hypercholesterolemia. J Clin Lipidol. 2017 May Jun;11(3):704-11 e2.

14. Beliard S, Boccara F, Cariou B, Carrie A, Collet X, Farnier M, et al. High burden of recurrent cardiovascular events in heterozygous familial hypercholesterolemia: The French Familial Hypercholesterolemia Registry. Atherosclerosis. 2018 Oct;277:334-40.

15. Law MR, Wald NJ, Rudnicka AR. Quantifying effect of statins on low density lipoprotein cholesterol, ischaemic heart disease, and stroke: systematic review and meta-analysis. BMJ. 2003 Jun 28;326(7404):1423.

16. Hicks KA, Mahaffey KW, Mehran R, Nissen SE, Wiviott SD, Dunn B, et al. 2017 Cardiovascular and Stroke Endpoint Definitions for Clinical Trials. J Am Coll Cardiol. 2018 Mar 6;71(9):1021-34.

17. Collins GS, Reitsma JB, Altman DG, Moons KG. Transparent Reporting of a multivariable prediction model for Individual Prognosis Or Diagnosis (TRIPOD). Ann Intern Med. 2015 May 19;162(10):735-6.

18. D'Agostino RB, Sr., Vasan RS, Pencina MJ, Wolf PA, Cobain M, Massaro JM, et al. General cardiovascular risk profile for use in primary care: the Framingham Heart Study. Circulation. 2008 Feb 12;117(6):743-53.

19. Civeira F, Castillo S, Alonso R, Merino-Ibarra E, Cenarro A, Artied M, et al. Tendon xanthomas in familial hypercholesterolemia are associated with cardiovascular risk independently of the low-density lipoprotein receptor gene mutation. Arterioscler Thromb Vasc Biol. 2005 Sep;25(9):1960-5.

20. Tada H, Kawashiri MA, Nohara A, Inazu A, Mabuchi H, Yamagishi M. Impact of clinical signs and genetic diagnosis of familial hypercholesterolaemia on the prevalence of coronary artery disease in patients with severe hypercholesterolaemia. Eur Heart J. 2017 May 21;38(20):1573-9.

21. Hoeg JM, Feuerstein IM, Tucker EE. Detection and quantitation of calcific atherosclerosis by ultrafast computed tomography in children and young adults with homozygous familial hypercholesterolemia. Arterioscler Thromb. 1994 Jul;14(7):1066-74.

22. Luirink IK, Wiegman A, Kusters DM, Hof MH, Groothoff JW, de Groot E, et al. 20-Year Follow-up of Statins in Children with Familial Hypercholesterolemia. N Engl J Med. 2019 Oct 17;381(16):1547-56.

23. Kusters DM, Wiegman A, Kastelein JJ, Hutten BA. Carotid intima-media thickness in children with familial hypercholesterolemia. Circ Res. 2014 Jan 17;114(2):307-10.

24. Den Ruijter HM, Peters SA, Anderson TJ, Britton AR, Dekker JM, Eijkemans MJ, et al. Common carotid intima-media thickness measurements in cardiovascular risk prediction: a meta-analysis. JAMA. 2012 Aug 22;308(8):796-803.

25. Miname MH, Bittencourt MS, Pereira AC, Jannes CE, Krieger JE, Nasir K, et al. Vascular age derived from coronary artery calcium score on the risk stratification of individuals with heterozygous familial hypercholesterolaemia. Eur Heart J Cardiovasc Imaging. 2019 Nov 8.

26. Perez de Isla L, Alonso R, Muniz-Grijalvo O, Diaz-Diaz JL, Zambon D, Miramontes JP, et al. Coronary computed tomographic angiography findings and their therapeutic implications in 
asymptomatic patients with familial hypercholesterolemia. Lessons from the SAFEHEART study. J Clin Lipidol. 2018 Jul - Aug;12(4):948-57.

27. Chiva-Blanch G, Padro T, Alonso R, Crespo J, Perez de Isla L, Mata P, et al. Liquid Biopsy of Extracellular Microvesicles Maps Coronary Calcification and Atherosclerotic Plaque in Asymptomatic Patients With Familial Hypercholesterolemia. Arterioscler Thromb Vasc Biol. 2019 May;39(5):945-55.

28. Ellis KL, Perez de Isla L, Alonso R, Fuentes F, Watts GF, Mata P. Value of Measuring Lipoprotein(a) During Cascade Testing for Familial Hypercholesterolemia. J Am Coll Cardiol. 2019 Mar 12;73(9):102939.

29. Perrot N, Theriault S, Dina C, Chen HY, Boekholdt SM, Rigade S, et al. Genetic Variation in LPA, Calcific Aortic Valve Stenosis in Patients Undergoing Cardiac Surgery, and Familial Risk of Aortic Valve Microcalcification. JAMA Cardiol. 2019 Jul 1;4(7):620-7.

30. Zewinger S, Kleber ME, Tragante V, McCubrey RO, Schmidt AF, Direk K, et al. Relations between lipoprotein(a) concentrations, LPA genetic variants, and the risk of mortality in patients with established coronary heart disease: a molecular and genetic association study. Lancet Diabetes Endocrinol. 2017 Jul;5(7):534-43.

31. Ference BA, Ginsberg HN, Graham I, Ray KK, Packard CJ, Bruckert E, et al. Low-density lipoproteins cause atherosclerotic cardiovascular disease. 1. Evidence from genetic, epidemiologic, and clinical studies. A consensus statement from the European Atherosclerosis Society Consensus Panel. Eur Heart J. 2017 Aug 21;38(32):2459-72.

32. Marston NA, Kamanu FK, Nordio F, Gurmu Y, Roselli C, Sever PS, et al. Predicting Benefit From Evolocumab Therapy in Patients With Atherosclerotic Disease Using a Genetic Risk Score: Results From the FOURIER Trial. Circulation. 2019 Nov 11. 
Figure $(n=3)$ and tables $(n=3)$ :

Figure 1: Patient flowchart for the REFERCHOL cohort for the analysis study and the validation study. $\mathrm{HeFH}=$ Heterozygous familial hypercholesterolemia. DLCN= Dutch Lipid Clinic Network

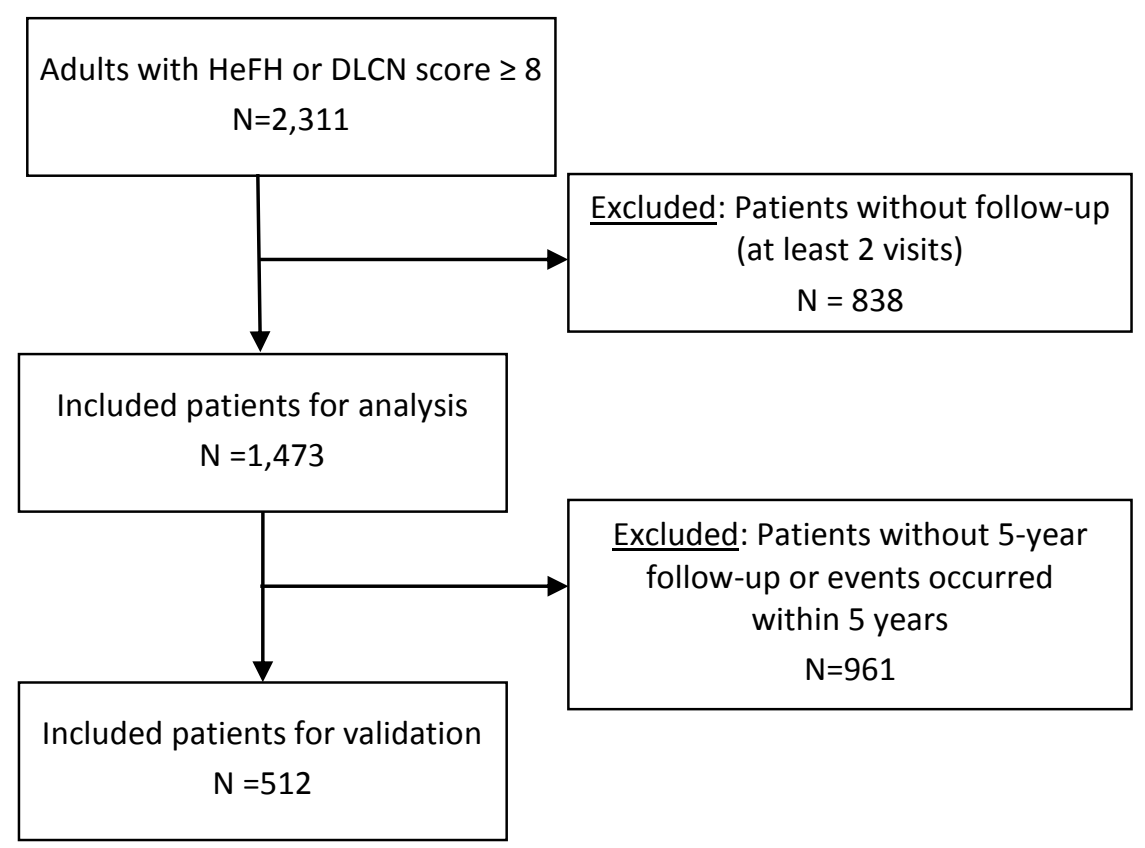


Table 1: Characteristics of the French REFERCHOL HeFH population at the enrolment visit

\begin{tabular}{|c|c|c|}
\hline Variable & Value & $\begin{array}{l}\text { REFERCHOL patients } \\
\qquad(\mathrm{N}=1473)\end{array}$ \\
\hline Gender (n) & Male & $712(48.34 \%)$ \\
\hline Age (years) & Mean (Sd) & $49.61(16.65)$ \\
\hline \multirow[t]{3}{*}{ Age (class) } & $<30$ & $244(16.56 \%)$ \\
\hline & $30-60$ & $794(53.90 \%)$ \\
\hline & $>60$ & $435(29.53 \%)$ \\
\hline \multirow[t]{4}{*}{ Mutation (n) } & Yes & $1032(70.06 \%)$ \\
\hline & LDL-R & $917(88.86 \%)$ \\
\hline & APOB & $80(7.75 \%)$ \\
\hline & PCSK9 & 35 (3.39\%) \\
\hline History of ASCVD (n) & Yes & $326(22.13 \%)$ \\
\hline $\begin{array}{l}\text { Premature history of familial ASCVD } \\
\text { (n) }\end{array}$ & Yes & $379(32.39 \%)$ \\
\hline Type II diabetes (n) & Yes & $61(4.39 \%)$ \\
\hline HTA (n) & Yes & $377(27.26 \%)$ \\
\hline Current smoker (n) & Yes & $369(27.05 \%)$ \\
\hline BMI $\left(\mathrm{Kg} / \mathrm{m}^{2}\right)$ & Mean (Sd) & $24.69(4.76)$ \\
\hline \multirow[t]{2}{*}{$\mathrm{TC}(\mathrm{mg} / \mathrm{dl})$} & Mean (Sd) & $277.12(91.21)$ \\
\hline & Median & 261.0 \\
\hline \multirow[t]{2}{*}{ Maximum TC (mg/dl) } & Mean (Sd) & $388.78(102.20)$ \\
\hline & Median & 376.0 \\
\hline \multirow[t]{2}{*}{ LDL-C (mg/dl) } & Mean (Sd) & $199.88(83.33)$ \\
\hline & Median & 186.0 \\
\hline \multirow[t]{2}{*}{ Maximum LDL-C(mg/dl) } & Mean (Sd) & $299.75(95.12)$ \\
\hline & Median & 288.5 \\
\hline \multirow[t]{2}{*}{ HDL-C (mg/dl) } & Mean (Sd) & $54.14(16.43)$ \\
\hline & Median & 52.0 \\
\hline \multirow[t]{2}{*}{ TG (mg/dl) } & Mean (Sd) & $111.72(69.24)$ \\
\hline & Median & 94.0 \\
\hline \multirow[t]{2}{*}{ ApoA1 (mg/dl) } & Mean (Sd) & 144.04 (32.39) \\
\hline & Median & 142.0 \\
\hline \multirow[t]{2}{*}{ ApoB (mg/dl) } & Mean (Sd) & $140.90(47.02)$ \\
\hline & Median & 130.0 \\
\hline \multirow[t]{2}{*}{$\operatorname{Lp}(\mathrm{a})$ (mg/dl) } & Mean (Sd) & $44.55(55.28)$ \\
\hline & Median & 25.0 \\
\hline Lp(a) > 50 mg/dl(n) & - & $265(31.36 \%)$ \\
\hline \multirow[t]{3}{*}{ Treatment(n) } & None & $491(33.33 \%)$ \\
\hline & Statins only & $464(31.50 \%)$ \\
\hline & Bitherapy & $517(35.10 \%)$ \\
\hline Maximum statin dose(n) & & $364(24.71 \%)$ \\
\hline Ezetimibe(n) & & $454(30.82 \%)$ \\
\hline Maximum combined therapy (n) & & $226(15.34 \%)$ \\
\hline LDL-apheresis & & $40(2.7 \%)$ \\
\hline \multirow[t]{2}{*}{ Time on statins (years) } & Mean (Sd) & $10.84(10.73)$ \\
\hline & Median & 8.0 \\
\hline \multirow[t]{2}{*}{ Age at initiation of statins (years) } & Mean (Sd) & $32.03(14.28)$ \\
\hline & Median & 30.9 \\
\hline \multirow[t]{2}{*}{ LDL-C-year-score (mg/dl) } & Mean (Sd) & $11.075(5.863)$ \\
\hline & Median & 10.424 \\
\hline \multirow{3}{*}{$\begin{array}{l}\text { LDL-C-year-score } \mathrm{mg} / \mathrm{dl} \\
\text { (Class) }\end{array}$} & $<6.000$ & $275(21.62 \%)$ \\
\hline & $6.000-16.000$ & 756 (59.20\%) \\
\hline & $>16.000$ & 244 (19.18\%) \\
\hline
\end{tabular}


ASCVD = AtheroSclerotic cardiovascular Disease. $S d=$ Standard deviation. A premature family history of ASCVD was defined as the occurrence of the first event before 55 years of age in men and before 65 years of age in women in first-degree relatives. Maximum statin dose was defined as atorvastatin 40 or $80 \mathrm{mg} /$ day, rosuvastatin 20 or $40 \mathrm{mg} /$ day, and simvastatin $80 \mathrm{mg} /$ day) (15). Maximum combined lipid-lowering therapy was defined as maximum statin dose plus ezetimibe $10 \mathrm{mg} /$ day. LDL-C-year-score $=\mathrm{LDL}-\mathrm{C}$ max * [age at diagnosis/initiation of statin] $+\mathrm{LDL}-\mathrm{C}$ at inclusion * [age at inclusion - age at diagnosis/initiation of statin]. 
Figure 2: Kaplan-Meier curves of freedom from cardiovascular event in all HeFH patients (black line), with history of CV event (blue line) or without history of CV event (green line). $\mathrm{CV}=$ cardiovascular.

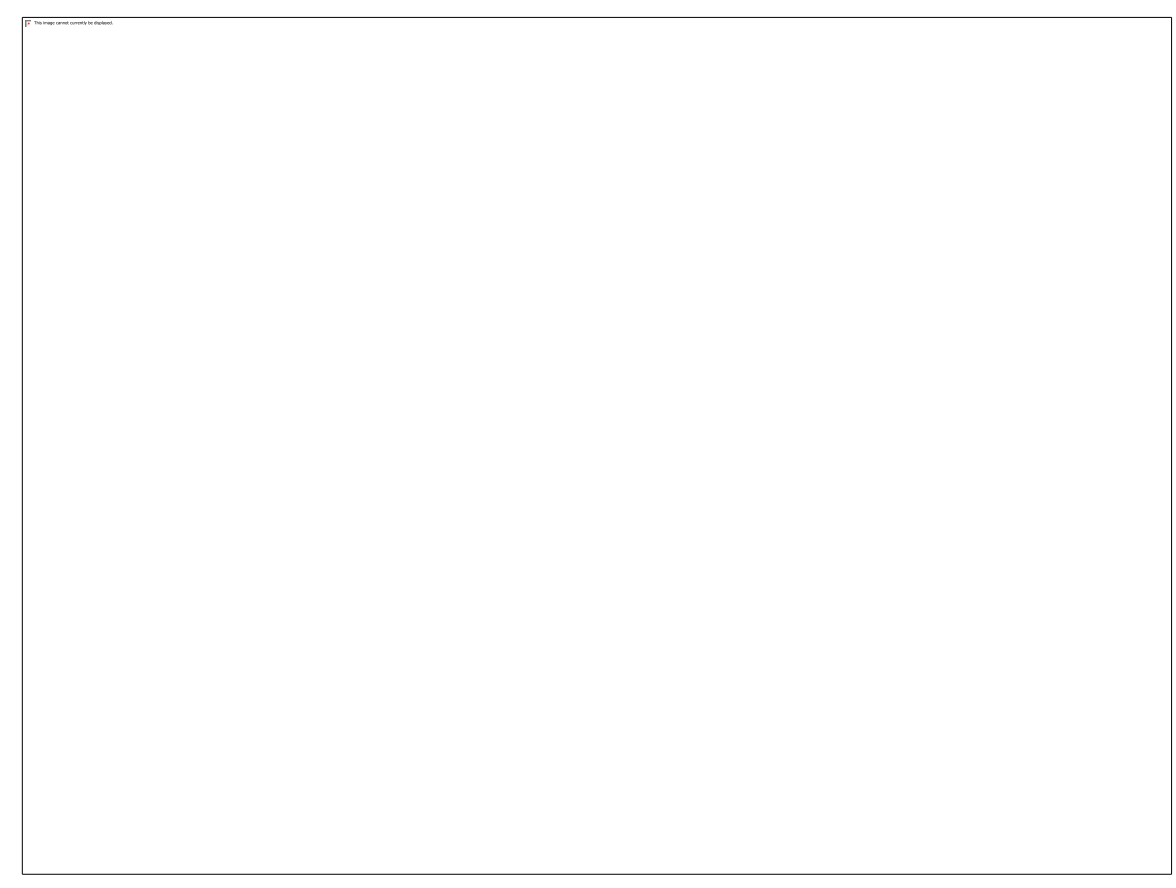


Table 2: Univariate analysis with Proportional Hazard Cox model for predicting CV events

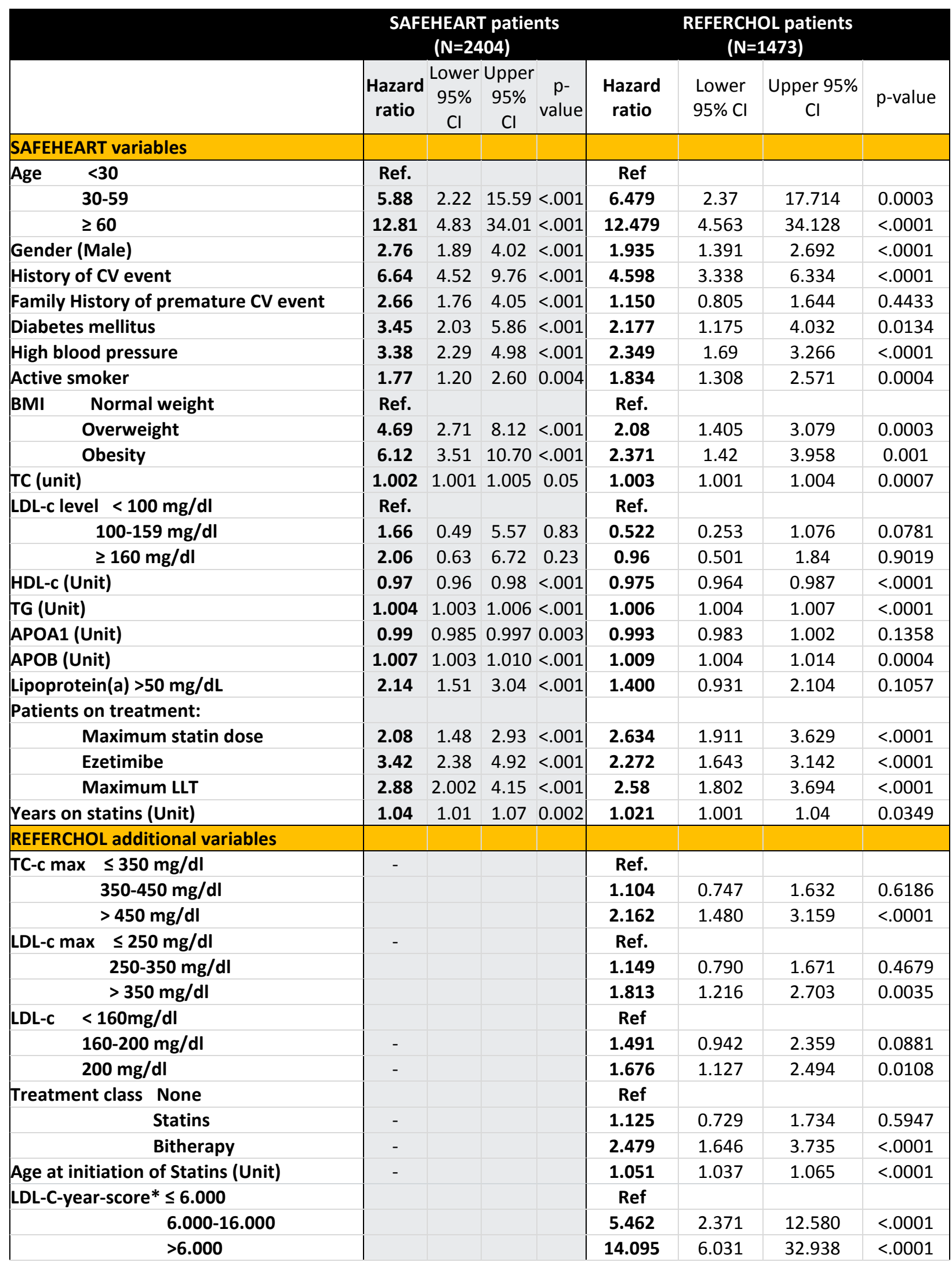

* Calculated by multiplying the highest LDL-C value by the patient's age at clinical diagnosis or initiation of statin therapy, to which was added the LDL-C value at the inclusion visit in the registry 
multiplied by the time spent until the inclusion visit, as follows: LDL-C-year-score $=L D L-C$ max * [age at diagnosis/initiation of statin] + LDL-C at inclusion * [age at inclusion - age at diagnosis/initiation of statin]. Sd= Standard deviation. A premature family history of ASCVD was defined as the occurrence of the first event before 55 years of age in men and before 65 years of age in women in patient's first-degree relatives. Maximum statin dose was defined as atorvastatin 40 or 80 mg/day, rosuvastatin 20 or 40 mg/day, and simvastatin 80 mg/day (15). Maximum LLT= maximum lipid lowering therapy was defined as maximum statin dose plus ezetimibe $10 \mathrm{mg} /$ day. $\mathrm{LDL}-\mathrm{C}$-year-score $=\mathrm{LDL}-\mathrm{C}$ max * [age at diagnosis/initiation of statin] $+\mathrm{LDL}-\mathrm{C}$ at inclusion * [age at inclusion - age at diagnosis/initiation of statin]. 
Table 3: Multivariate analysis with Proportional Hazard Cox model for predicting CV events

\begin{tabular}{|c|c|c|c|c|c|c|c|c|c|c|c|c|}
\hline & \multicolumn{4}{|c|}{$\begin{array}{l}\text { SAFEHEART patients } \\
\qquad(\mathrm{N}=2404)\end{array}$} & \multicolumn{4}{|c|}{$\begin{array}{l}\text { REFERCHOL patients } \\
\qquad(\mathrm{N}=1473) \\
\frac{\text { Forcing SAFEHEART }}{\underline{\text { variables }}}\end{array}$} & \multirow{2}{*}{\multicolumn{4}{|c|}{$\begin{array}{l}\text { REFERCHOL patients } \\
(\mathrm{N}=1473) \\
\frac{\text { No Forcing }}{\text { (Selection of significant }} \\
\underline{\text { variables only) }}\end{array}$}} \\
\hline & \multicolumn{4}{|c|}{ SAFEHEART equation } & \multicolumn{4}{|c|}{ REFERCHOL Equation - A } & & & & \\
\hline & $\begin{array}{l}\text { Hazard } \\
\text { ratio }\end{array}$ & $\begin{array}{c}\text { Lowe } \\
r \\
95 \% \\
\mathrm{Cl} \\
\end{array}$ & $\begin{array}{c}\text { Upper } \\
95 \% \\
\mathrm{Cl}\end{array}$ & $\begin{array}{c}p- \\
\text { value }\end{array}$ & $\begin{array}{l}\text { Hazar } \\
\text { d ratio }\end{array}$ & $\begin{array}{c}\text { Lower } \\
95 \% \\
\mathrm{Cl}\end{array}$ & $\begin{array}{c}\text { Upper } \\
95 \% \\
\mathrm{Cl}\end{array}$ & $\begin{array}{c}p- \\
\text { value }\end{array}$ & $\begin{array}{c}\text { Hazard } \\
\text { ratio }\end{array}$ & $\begin{array}{c}\text { Lower } \\
95 \% \\
\mathrm{Cl}\end{array}$ & $\begin{array}{l}\text { Upper } \\
95 \% \mathrm{Cl}\end{array}$ & $\begin{array}{c}p- \\
\text { value }\end{array}$ \\
\hline$<30$ & & & & & Ref & & & & & & & \\
\hline $30-59$ & 2.92 & 1.14 & 7.52 & 0.026 & 3.474 & 1.235 & 9.768 & 0.0182 & & & & \\
\hline$\geq 60$ & 4.27 & 1.60 & 11.48 & 0.004 & 5.452 & 1.883 & 15.787 & 0.0018 & & & & \\
\hline Gender (Male) & 2.01 & 1.33 & 3.04 & 0.001 & 1.335 & 0.889 & 2.005 & 0.1643 & & & & \\
\hline History of CV event & 4.15 & 2.55 & 6.75 & $<.001$ & 4.192 & 2.783 & 6.314 & $<.0001$ & 5.774 & 3.378 & 9.868 & $<.0001$ \\
\hline High blood pressure & 1.99 & 1.26 & 3.15 & 0.003 & 1.085 & 0.718 & 1.637 & 0.6992 & & & & \\
\hline Active smoker & 1.62 & 1.08 & 2.44 & 0.02 & 1.680 & 1.129 & 2.500 & 0.0106 & 2.146 & 1.283 & 3.587 & 0.0036 \\
\hline BMI Normal weight & Ref & & & & Ref & & & & & & & \\
\hline Overweight & 2.40 & 1.36 & 4.23 & 0.002 & 1.052 & 0.694 & 1.594 & 0.8113 & & & & \\
\hline Obesity & 2.67 & 1.47 & 4.85 & 0.001 & 1.585 & 0.914 & 2.750 & 0.1011 & & & & \\
\hline LDL-c level* < $100 \mathrm{mg} / \mathrm{dl}$ & Ref & & & & $\operatorname{Ref}^{\star}$ & & & & $\operatorname{Ref}^{*}$ & & & \\
\hline $100-159 \mathrm{mg} / \mathrm{dl}$ & 2.50 & 0.60 & 10.53 & 0.21 & 2.261 & 1.359 & 3.759 & 0.0017 & 2.925 & 1.469 & 5.826 & 0.023 \\
\hline$\geq 160 \mathrm{mg} / \mathrm{dl}$ & 4.80 & 1.15 & 20.01 & 0.032 & 3.348 & 2.094 & 5.353 & $<.0001$ & 3.261 & 1.625 & 6.546 & 0.0009 \\
\hline Lipoprotein (a) > 50 mg/dl & 1.52 & 1.05 & 2.21 & 0.028 & 1.413 & 0.929 & 2.149 & 0.1059 & & & & \\
\hline LDL-C-year-score $\leq 6.000$ & & & & & & & & & $\operatorname{Ref}$ & & & \\
\hline 6.000-16.000 & & & & & & & & & 5.685 & 0.761 & 42.491 & 0.0904 \\
\hline$>16.000$ & & & & & & & & & 17.403 & 2.309 & 131.172 & 0.0056 \\
\hline
\end{tabular}

33 * LDL-C level: < $160 \mathrm{mg} / \mathrm{dl}$ (Reference); 160-200 mg/dl; $\geq 200 \mathrm{mg} / \mathrm{dl}$ for REFERCHOL Equation A and B. LDL-C- 
Figure 3: ROC curves for REFERCHOL-RE A, SAFEHEART-RE, and LDL-C-year-score.
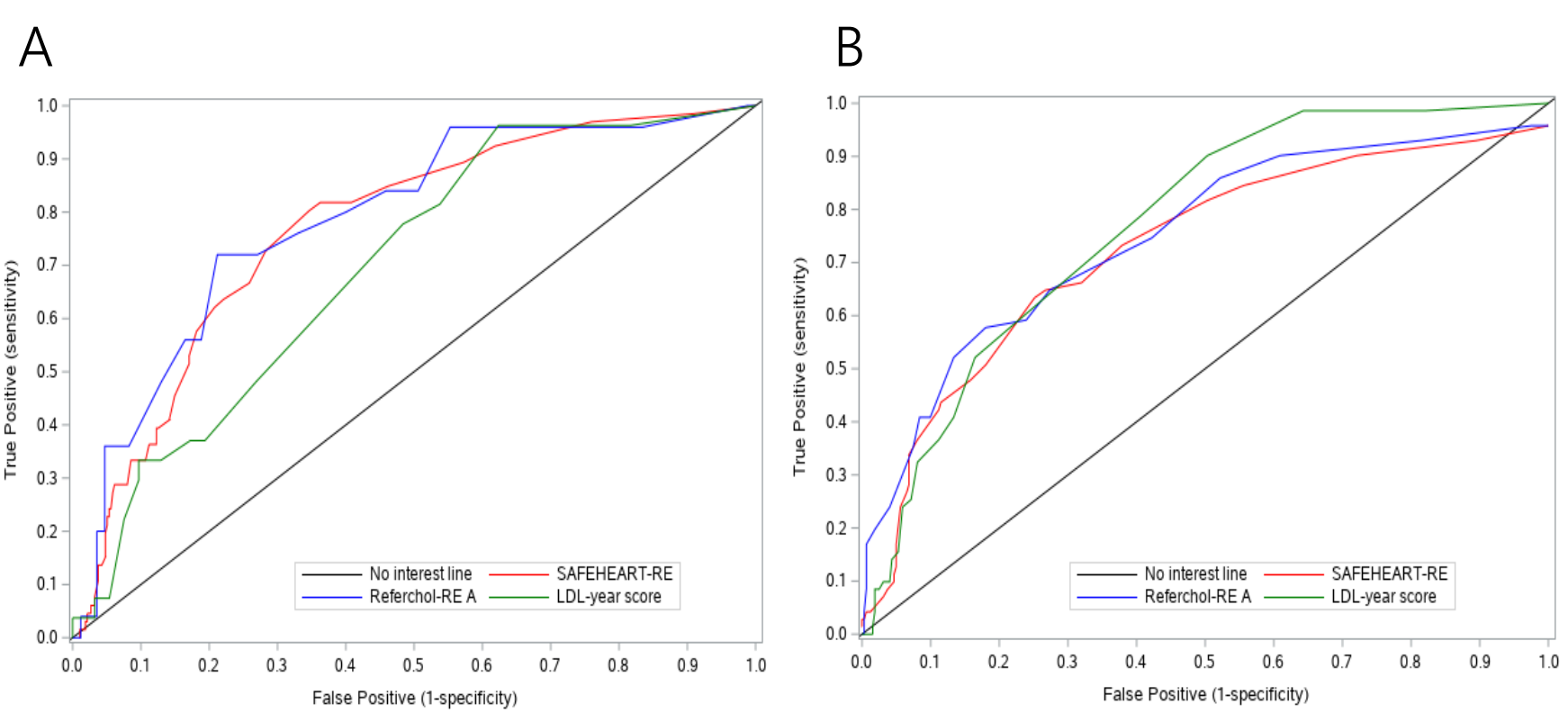

21

22 


\section{REBUTTAL LETTER TO THE EDITOR AND THE REVIEWERS:}

Dear Dr. Arnold von Eckardstein, Dr. Gerald F Watts and Dr. Jan Borén,

Thank you for reviewing our manuscript entitled "SAFEHEART risk-equation and cholesterol-year-score are powerful predictors of cardiovascular events in French patients with Familial Hypercholesterolemia" (Ms. No. ATH-D-20-00496). We again thank the reviewers for their overall positive comments and for the pertinent points they have raised. Please find attached our responses to the comments of the reviewers in a point-by-point fashion. We have indicated clearly in each case the revisions to the manuscript that address his/her suggestions, in red in the text. We feel that the manuscript has benefited significantly from their critiques and we hope that you will now find it acceptable for publication in the journal "Atherosclerosis".

Yours sincerely,

Dr SOPHIE BELIARD, MD, PhD

Marseille, the 04 June 2020,

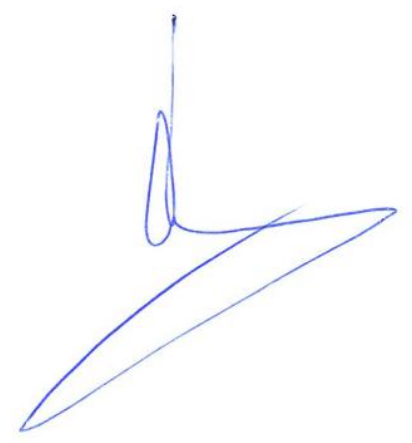

\section{Responses to Reviewer\#1:}

We thank the reviewer for his/her very positive and encouraging assessment of this manuscript and for the pertinent points he/she has raised.

"Gallo et al validated SAFEHEART-risk-equation and compare with LDL-C year score in the French cohort. A vaid CV risk equcation is important for $\mathrm{FH}$ maangement. The manauscript is a well-written manusript with detailed/appropriate statistical analysis. I have no major issue on the results and intrepreation. L $L(a)$ was not a significant predicitor of CV events". 


\section{Please provide kit details for $\operatorname{Lp}(a)$ measurement:}

The majority of $L p(a)$ measurements were made by using an immunonephelemetric method (Siemens- France). However, some Lp(a) measurements were made with alternatives methods outside in laboratories of other University Medical Centres, the latter corresponding to the location of heFH patients. We added this point in red in the Patients and Method section, page5.

\section{Would $L p(a)$ be a predictor as a continuous variable or using other cut-cut off values were} employed e.g $30 \mathrm{mg} / \mathrm{dL}$ or $80 \mathrm{mg} / \mathrm{dL}$ ?

We thanks the reviewer 1 for this pertinent question. We decided to use the $50 \mathrm{mg} / \mathrm{dL}$ cut-off for two main raisons. First, as the subject of this study was to validate SAFEHEART-RE in the French cohort, we decided to use exactly the same variables as those used in the SAFEHEARTRE. Secondly, the $50 \mathrm{mg} / \mathrm{dL}$ cut-off is discriminant for the isolation of the $90^{\text {th }}$ percentile of the general population.

As you required, we tested if $L p(a)$ as a continuous variable was predictive of the occurrence of a CV event in univariate analysis in the REFERCHOL cohort (table 1), age-adjusted or not. We did not found that $\mathrm{Lp}(\mathrm{a})$ as a continuous variable was statistically correlated to CV events, even though we found a clear tendency with a limit $p$ value at 0.09 . Our results probably lack power, as $L p(a)$ is a known CV risk factor.

\begin{tabular}{|c|c|c|c|c|c|c|c|c|}
\hline & \multicolumn{4}{|c|}{$\begin{array}{l}\text { SAFEHEART patients } \\
\qquad(\mathrm{N}=\mathbf{2 4 0 4})\end{array}$} & \multicolumn{4}{|c|}{$\begin{array}{l}\text { REFERCHOL patients } \\
\qquad(\mathrm{N}=1473)\end{array}$} \\
\hline & $\begin{array}{c}\text { Hazard } \\
\text { ratio }\end{array}$ & $\begin{array}{l}\text { Lower } \\
95 \% \\
\mathrm{Cl}\end{array}$ & $\begin{array}{l}\text { Upper } \\
95 \% \\
\mathrm{Cl}\end{array}$ & value & $\begin{array}{c}\text { Hazard } \\
\text { ratio }\end{array}$ & $\begin{array}{l}\text { Lower } \\
95 \% \mathrm{Cl}\end{array}$ & $\begin{array}{c}\text { Upper 95\% } \\
\mathrm{Cl}\end{array}$ & $\mathrm{p}$-value \\
\hline \multicolumn{9}{|l|}{ SAFEHEART variables } \\
\hline Lipoprotein(a) (unit, mg/dL) & - & - & - & - & 1.002 & 1.000 & 1.005 & 0.0984 \\
\hline Lipoprotein(a) (unit, mg/dL), age-adjusted & - & - & - & - & 1.002 & 0.999 & 1.005 & 0.1936 \\
\hline
\end{tabular}

Table: Univariate analysis with Proportional Hazard Cox model for predicting CV events for Lp(a) as a continuous variable

\section{Had LDL-C been adjusted for Lp(a) cholesterol?}


No, LDL-cholesterol has not been adjusted for the $L p(a)$ cholesterol. As the LDL-cholesterol was not directly dosed but was calculated by the Friedwald formula, LDL-cholesterol is the composite of the cholesterol in the LDL particles and the $\operatorname{Lp}(a)$ particles. That means, that the LDL-year-score also take into account the cholesterol contained in the Lp(a) particles.

\section{It is of interest to explore $L p(a)$ - year score whether it predicts CV events.}

You're right, it would be of interest to test a Lp(a)-year score. However, Lp(a) level is known to be lifelong stable, with no treatment for decreasing its level (except PCSK9 inhibitors which are few prescribed in France and since only two years). So a "Lp(a) year score" would be an age-adjusted Lp(a) level. As we showed in the question 2 (table 1), we tested in univariate analysis if age-adjusted-Lp(a) as a continuous variable was predictive of the occurrence of a $\mathrm{CV}$ event and results were negatives. As we already said in the previous answer, our results probably lack power, as Lp(a) is a known CV risk factor.

\section{Responses to Reviewer\#2:}

We thank the reviewer for his/her very positive and encouraging assessment of this manuscript and for the pertinent points he/she has raised.

Gallo et al.Gallo A et al, analized the National French register of FH (REFERCHOL) with the main objective to validate the Spanish SAFEHEART-RE (SF-RE), and secondly to compare the predictive power of SF-RE with LDL-C year score.

They used $1473 \mathrm{FH}$ patients from the registry with clinical and/or genetic diagnosis of FH with at least 2 visits in the follow-up. Specifically, for the validation of the SF-RE, they included 512 patients with a follow-up at least 5 years. Some variables were modified due to differences in samples size (mainly related to $L D L-C$ ).

For the LDL-C year score, they used the highest LDL-C at clinical diagnosis or initiation of statin therapy (obtained from the medical record) and then the LDL-C at the inclusion visit. Each value multiplied by the age in each moment, and then added.

Methods and Statistics are well explained

Main results:

In UV analysis, all parameters included in the SF-RE except family history of PCV and Lp(a) levels $>50$ were statistically significant with HR with similar range. 
In the REFERCHOL cohort, LDL-C year score was a strong predictor in UV model.

In MV analysis, forcing the inclusion of all variables (A) from SAFEHEART, age, history of CV events, tobacco, and LDL-C leves were significant predictors. In option B including only significant variables in UV analysis, history of CV disease, tobacco, LDL-C and LDL-C years score were the independent predictors. The strongest predictor was LDL-C years score (17 times with a value > 16000).

For the validation of the SF-RE (the main objective of this study), the C-index for SF-RE, REFERCHOL $A$ and LDL-C years score were: $0.77,0.78$ and 0.70 respectively.

LDL-C year score was less effective than the other 2 models.

In FH patients free of CV events at inclusion, all 3 models were good predictors (C-index 0.78, 0.79 and 0.77$)$. No conclusion regarding patients with CV events at inclusion could be obtained by the sample size.

This is a novel and very interesting manuscript because it is the first external validation of the SF-RE, and probably also of the LDL-C year score in FH population.

The SF-RE was the first specific CV risk equation developed in a genetically confirmed heterozygous FH population from Spain, followed-up prospectively, including clinical and laboratory variables used in routine clinical practice in the evaluation of FH patients.

1) Although not described in the discussion the SF-RE correlates with the CAC Score (J Clin Lipidol. 2018;12(4):948-957) and with other biological parameters such as circulating microvesicles that may be surrogate biomarkers of coronary calcification in FH patients (ATVB 2019;39:945-955.DOI: 10.1161/ATVBAHA.118.312414). SF-RE shows strong clinical evidence and relates to as well as biological and image data.

We added this precise point on the correlation of SAFEHEART-RE with imaging data and circulating biomarkers of coronary calcifications in $\mathrm{FH}$ in the discussion, in red, page 13. We then added these two references (in red in the bibliography).

2) There are some differences among both populations like Age: 45 in SF vs 49 , BMI 26.5 vs. 24.7, Lp(a) 38.2 vs. 44.55. Most patients in Safeheart were receiving LLT at inclusion. In the case of SAFEHEART Lp(a) was measured centralized. It is probably than in REFERCHOL; Lp(a) was measured in different labs with different methods and that's why the results may differ. 
You are absolutely right, Spanish and French populations differ on many points as the age, the $\mathrm{BMI}$, the number of treated patients. Also, $\mathrm{Lp}(\mathrm{a})$ measurements were not centralized as in SAFEHEART study. However, a large proportion of $L p(a)$ measurements were made by using an immunonephelemetry method (Siemens- France). However, some Lp(a) measurements were made with various other methods outside from the university hospital. We added this point in red in the Patients and Method section, page 5.

3) Regarding LDL-C year score, this study also validates its utility. It is important to point out that this score was first used in homozygous FH patients $(n=17)$, and its validation in heterozygous FH is scarce.

We added your pertinent remark in the introduction page 5 in red.

4) LDL-C years score or Cholesterol year score is supposed to be an easy and simple tool to determine the burden of disease (cholesterol burden associated to atherosclerotic burden). In this study, in the MV analysis, it is a strong predictor in values over 16.000 with a wide $\mathrm{Cl}$ (2.39 to 131.7). It is important to remark in the discussion some practical issues, like to get the highest values of TC or LDL -C in patients can be difficult nowadays (except if they are recorded) because most of them are under long-term treatment and do not remember baseline values (practical issue). Also, values of LDL-C are susceptible of changes during time by modification in lipid-lowering treatments. In this sense, is the same as risk a patient that took medication during years and discontinued by other amount of years ??

You are right, LDL-C-year-score is an approximate data reflecting the lifelong cholesterol burden, but it is a good predictor of $\mathrm{CV}$ events in $\mathrm{FH}$. It is approximate because the maximal cholesterol value, ie without treatment, is often hard to find. However many patients kept their old biological analyses with their lipid results before treatment initiation, and we could retrieved this data in the majority of the cases. Secondly, as you mentioned, some patients stop medications for some months or years for several reasons (pregnancy, statins intolerance etc.). We constructed the LDL-C year score with several LDL-C levels along the time (with or without lipid lowering therapy). Finally, the LDL-C year score is as approximate as the packyear measuring lifelong exposure to tobacco, but it works to predict CV events in this $\mathrm{FH}$ cohort. 
5) Considering the risk as a continuum, the SH-RE seems to be a good tool if all variables are available. Therefore, it can be used in both primary and secondary prevention. For the entire cohort (primary and secondary prevention) the SF-RE is better; and is close similar to LDL-C year score in primary prevention. In the conclusion authors need to point out that SF-RE is a better predictor in both primary and secondary prevention. In addition, this validation can strengthen the use of SF-RE as an easy and accurate tool in other countries. As you required, we added this sentence in the conclusion, page 14 (in red in the text):

Both SAFEHEART and cholesterol-year-score were powerful predictors of CV events in primary prevention. However, in the entire cohort (ie. Including both primary and secondary prevention patients), SAFEHEART was superior to the cholesterol-year-score. This first external validation of the SAFEHEART-RE is promising as it validates the wider applicability of SAFEHEART-RE in other HeFH populations. 
Marseille, April $15^{\text {th }}$ 2020,

Dr A. von Eckardstein

\section{Editor in Chief}

\section{Statement of originality:}

Dear A. von Eckardstein,

I certify that the data of the present study are my own work and have not been published in this or any substantially similar form, nor accepted, nor is it under consideration for publication elsewhere.

All authors have contributed to the preparation and development of this manuscript, and have approved the final draft prior to submission.

Thank you for considering the manuscript and I look forward to hearing from you.

Yours sincerely

Sophie BELIARD-LASSERRE, MD, PhD

APHM, Aix Marseille University, France

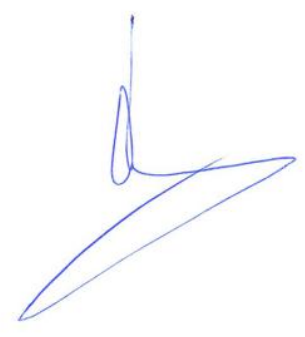


Marseille, April $15^{\text {th }}$ 2020,

\section{Dr A. von Eckardstein}

\section{Editor in Chief}

Dear A. von Eckardstein,

\section{This is the conflict of interest form for the present work:}

SB have received honoraria for board, conferences, clinical trial or congress from Aegerion, Akcea, Elivie, Sanofi or Amgen. AV and VC has no conflict of interest to declare. E.B. reports grants from Sanofi and Amgen, and personal fees from Aegerion, Danone, Genfit, MSD, Sanofi/Regeneron Pharmaceuticals, Inc., AstraZeneca, Servier, AMGEN, AKCEA, Mylan.

AG, FB, AC, BC, SC, DA have received honoraria for boards, and/or conferences, and/or clinical trial and/or congress from Sanofi or Amgen.

Thank you for considering the manuscript and I look forward to hearing from you.

Yours sincerely

Sophie BELIARD-LASSERRE, MD, PhD

APHM, Aix Marseille University, France

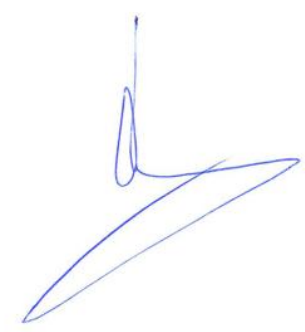


Click here to access/download

Supplementary Material for online publication only
supplemental data atherosclerosis.docx 
All authors have contributed to the preparation and development of this manuscript, and have approved the final draft prior to submission. 